\title{
Sensory Comparison of Bread Crumb with and without Crust
}

\author{
Katharina Fuckerer ${ }^{1}$, Oliver Hensel ${ }^{2}$ \& Joachim J. Schmitt ${ }^{1}$ \\ ${ }^{1}$ Department of Food Technology, University of Applied Science Fulda, Fulda, Germany \\ ${ }^{2}$ Faculty of Organic Agricultural Sciences, Department of Agricultural Engineering/Livestock Systems Engi- \\ neering, University of Kassel, Kassel, Germany \\ Correspondence: Katharina Fuckerer, Department of Food Technology, University of Applied Science Fulda, \\ Leipziger Straße 123, 36039 Fulda, Germany. Tel: 49-(0)661-9640-541. E-mail: \\ Katharina.Fuckerer@lt.hs-fulda.de
}

Received: May 4, 2015 Accepted: June 10, 2015 Online Published: July 31, 2015

doi:10.5539/jfr.v4n5p33 URL: http://dx.doi.org/10.5539/jfr.v4n5p33

\begin{abstract}
Rye-bread belongs to traditional food in Europe and is preferred by elderly people in Germany. But those people often have difficulties with chewing the firm crust of those breads which, therefore, gets cut off. Current opinion suggests that flavor substances, produced during baking, diffuse from crust to crumb and therefore, bread baked with weak or without crust does not taste well. In present study, however, it was determined by triangle tests as well as color and firmness measurements, that crumb of crustless bread is nearly similar to crumb of bread with crust.
\end{abstract}

Keywords: crumb, crustless, rye bread, sensory

\section{Introduction}

Bread is part of basic food, where the average consumption per person per year is $50 \mathrm{~kg}$ in Europe (FoB, 2010). In Germany bread consumption is even above $80 \mathrm{~kg}$ per person per year (Heseker, 2008).

Since rye-bread belongs to traditional food, many elderly people prefer eating this bread despite the fact that many very old people often have chewing and swallowing difficulties (Fillion \& Kilcast, 2001; Morley, Glick, \& Rubenstein, 1995; Rehrmann, 2007; Volkert, Kruse, Oster, \& Schlierf, 1991). Therefore those elderly could chew bread without crust more easily and prefer this. The flavor of crumb of crustless bread has to be similar to crumb of bread with crust, because consumer taste is a key attribute of bread (Heiniö, 2006). Therefore it is necessary that crustless bread tastes like bread with crust.

Flavor of bread depends on ingredients (Baker \& Mize, 1939; Visser't Hoft \& De Leeuw, 1935) and substances produced during fermentation (Baker \& Mize 1939; Baker, Parker \& Fortmann, 1953; Robinson, Lord, Johnson \& Miller, 1958; Salim-ur-Rehman, Paterson, \& Pigott, 2006; Visser’t Hoft \& De Leeuw, 1935; Wiseblatt, 1957). Baker and Mize (1939) and Baker et al. (1953) concluded in their studies, that flavor of bread is influenced by heat reactions in the crust during baking, e. g. maillard reaction. Lindenmeier and Hofmann (2004) also determined that maillard reaction influenced formation of typical bread flavor.

Previous literature assumed that there is a diffusion of flavor substances from crust to crumb. So Baker and Mize (1939) maintained those flavor products from the crust, formed during baking, that reached the crumb. Lorenz and Maga (1972) assumed that aldehydes diffuse from the crust into the crumb via partial diffusion during aging. Thus those authors are convinced that crust influences the flavor of the crumb and that crustless bread offered unacceptable odor and flavor (Wiseblatt, 1961).

These results indicate that there is a sensory difference between crumb of bread with crust and crumb of bread without crust.

Therefore the aim of the following study was to identify if there is a difference between the crumb of bread with crust and the crumb of bread without crust. Both crumbs were compared and an investigation taken based on color and firmness measuring and in addition by sensory triangle test of differences and similarity.

\section{Experimental}

Bread was baked under laboratory conditions following the recipe shown in Table 1. 
Table 1. Recipe for a kilogram of dough

\begin{tabular}{|c|c|}
\hline Ingredientes & [g] \\
\hline Rye flour type $997^{\text {a }}$ & 415.2 \\
\hline Wheat flour type $550^{\mathrm{a}}$ & 135.1 \\
\hline Breadcrumbs & 11.5 \\
\hline Dry Auer (Diamalt) ${ }^{\mathrm{a}}$ & 16.5 \\
\hline Yeast $(\text { S. cerevisiae })^{b}$ & 7.5 \\
\hline Salt & 11.5 \\
\hline Water (pre-warmed $37^{\circ} \mathrm{C}$ ) & 402.7 \\
\hline
\end{tabular}

${ }^{\mathrm{a}}$ provided by bakery Storch, Fulda.

${ }^{b}$ stored at $4^{\circ} \mathrm{C}$.

\subsection{Dough Preparation}

Dough was prepared traditionally. Ingredients were kneaded with the dough kneader (Typ S20G3, DIOSNA, Osnabrück, Germany) initially for five minutes at Level 1 (60 strokes/ min) and a further five minutes at Level 2 (120 strokes/ min). Dough resting followed for 30 minutes at a temperature of $22{ }^{\circ} \mathrm{C}$ and was afterwards covered with a damp cloth. The dough was split up into six parts of $800 \mathrm{~g}$. Each part was cylindrically kneaded and added to a fatted iron baking pan. Subsequently, the raw dough was incubated for one hour at $35{ }^{\circ} \mathrm{C}$ and $80 \%$ humidity in the proofing cabinet (Typ AEG5, MIWE, Arnstein, Germany) for the rising process.

\subsection{Baking Procedure for Crustless Bread}

Crustless brown bread (shown in Figure 1) was baked in a preserving pan (Typ abc 1410, Westfalia, Hagen, Germany), which was filled with 11 of water. Before baking, the preserving pan was heated to $100{ }^{\circ} \mathrm{C}$ so that water started to steam. Then baking pans, each covered with a second metal pan on top, were placed into the steaming water for baking. Loaves of bread were baked for 70 minutes and ended up with a core temperature of $95^{\circ} \mathrm{C}$.

\subsection{Baking Procedure for Bread With Crust}

Breads with crust (shown in Figure 1) were baked in conventional oven (Type CE 416/77H, Winkler Wachtel, Hilden, Germany). The Oven was heated to $200{ }^{\circ} \mathrm{C}$ and the baking process took place for 50 minutes until the bread with crust had the core temperature of $95^{\circ} \mathrm{C}$. For the first 5 minutes the slide damper was open and steam was added for 5 seconds.

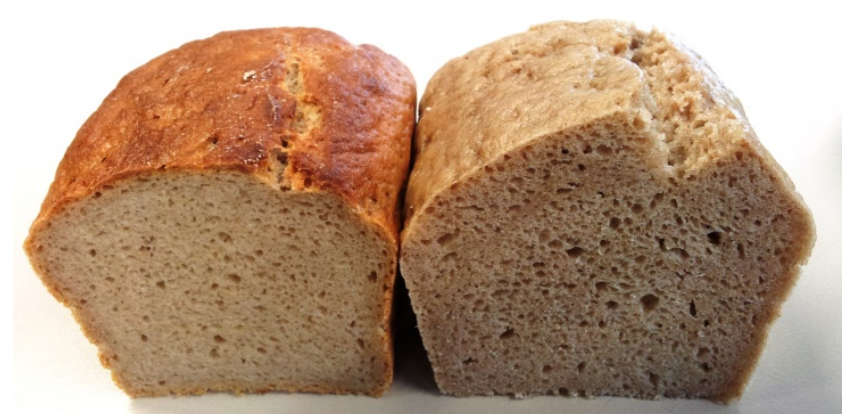

Figure 1. Rye bread with crust (left) and without crust (right)

\subsection{Color and Firmness Measurement}

The Color of both crumbs were measured with spectro-color-meter (Typ LMG 183, Hach-Lange, Berlin, Germany), after standardization with a white and black calibration plate. The color was recorded using CIE-L*a*b* uniform color space (CIE-Lab), where $L^{*}$ indicates lightness, $a *$ indicates coloring on a green (-) to red (+) axis and $b^{*}$ indicates coloring on a blue (-) to yellow (+) axis. The spectral curves were determined over 400-700 nm range using illuminant D65 and with a $10^{\circ}$ standard observer. Color difference between crustless crumb and crumb with crust was calculated, using the following Equation (1): 


$$
\Delta E=\sqrt{\left[\left(L_{1}^{*}-L_{2}^{*}\right)^{2}+\left(a_{1}^{*}-a_{2}^{*}\right)^{2}+\left(b_{1}^{*}-b_{2}^{*}\right)^{2}\right]}
$$

Note: $\mathrm{L}_{1}{ }^{*}, \mathrm{a}_{1}{ }^{*}$ and $\mathrm{b}_{1}{ }^{*}$ : Values of crustless crumb bread; $\mathrm{L}_{2}{ }^{*}, \mathrm{a}_{2}{ }^{*}$ and $\mathrm{b}_{2}{ }^{*}$ : Values of crumb bread with crust.

Crumb firmness was measured using a TA-XT Plus texture analyzer (Stable-Micro-Systems, Surrey, Surrey, Great Britain), which measured maximal force in Newton. Slices of $25 \mathrm{~mm}$ were compressed $9.5 \mathrm{~mm}$ with a cylindrical probe (diameter: $35 \mathrm{~mm}$, contact: $962 \mathrm{~mm}^{2}$, cylinder aluminum) and with a test speed of 1.00 $\mathrm{mm} / \mathrm{sec}$.

For the color and firmness measurement three cooled ( 3 hours) slices of bread from the center of the loaves were measured and three breads were measured each day. Hence 27 values of each crumb type were determined.

\subsection{Storage of Breads for Sensory Test}

After baking, both bread types were cooled for three hours and sliced in $1.0 \mathrm{~cm}$ thick slices. Sliced loaves of bread were kept in dense plastic bags for 20 hours at room temperature.

\subsection{Sensory Analyses}

Similarity Tests were performed by using the triangle method (DIN EN ISO 4120: 2007) and to determine if the crumb of bread with crust was similar to the crumb of bread without crust. For the triangle test panelists have to evaluate three samples, two are identical and one is different. Panelists were asked to pick the sample that is different. Triangle test is a forced-choice test, so that panelists have to choose a sample as the different one.

Prior to testing one round piece was cut out from the middle of the crumb of a slice of bread with, respectively, without crust. The samples had a diameter of $3.3 \mathrm{~cm}$ and a thickness of $1.0 \mathrm{~cm}$. Sensory analyses were conducted in the sensory laboratory of University of Fulda and were performed by 37 voluntary panelists ( 20 male, 17 female, mean age 25.6) who had experience with bread (participation at sensory test with bread), but were untrained in regard to the triangle test. All participants were students with normal olfactory and gustatory function and from University of Fulda. Untrained panelists were chosen to determine whether consumers detect the difference between both crumbs.

Bread crumbs were tested in three different ways over a two week period. During one session a panelist analyzed four different triangles. Hence 148 triangles were tested. Bread samples were served in small glass bowls at room temperature $\left(23^{\circ} \mathrm{C}\right)$ and were coded with a three-digit random number. Each triangle had a different and random order of the samples, so that one triangle was built of two samples of crumb of crustless bread and one samples of crumb with crust. Another triangle was built of two samples of crumb of bread with crust and one crumb sample of crustless bread. Each panelist received four random, different orders of the triangles. Therefore all serving orders were analyzed (AAB, ABA, BAA, BBA, BAB, ABB). Four of six possible combinations were researched, because more than four triangles could overburden panelists. The four combinations were selected randomly. Pure water was served for neutralization. The panelists were informed that one of the samples was different from the others and were asked to identify this sample and to explain their decision. If a panelist were unable to detect a difference between all three samples, they were instructed to make a guess and to note that it was so.

\subsection{Statistical Analysis}

Means and standard deviations of color and firmness measurement were calculated with SPSS statistical software (Version 20.0, SPSS, Chicago, USA). Normal distribution was determined with Shapiro-Wilk-Test ( $\mathrm{p}=$ $0.05)$ and test of homogeneity of variance was passed by Levene Test $(\mathrm{p}=0.05)$. Significant differences $(\mathrm{p}<$ 0.05 ) among crustless bread and bread with crust were calculated with single-factor ANOVA.

Sensory test results were analyzed by a statistical significance template for triangle tests of similarity (Meilgaard, Civille, \& Carr, 1999; Quadt, Schwarz, \& Schönberger, 2009) according on a binomial distribution. Parameters for triangle method of similarity were defined with $\alpha$-risk-level of 0.01 (probability of concluding that a perceptible difference exists when 1 does not) and $\beta$-risk-level of 0.01 (probability of concluding that no perceptible difference exists when 1 does) and $p_{\mathrm{d}}$-level of 0.3 (true proportion of population able to detect a difference between samples). A $p_{d}$-level of 0.3 was chosen because it equates a medium range of population, which are able to detect difference between samples (Busch-Stockfisch 2003).

\section{Results}

\subsection{Color Measurement}

$\mathrm{L}^{*} \mathrm{a}^{*} \mathrm{~b}^{*}$-values of both crumb types are shown in Table 2. Lightness values $\left(\mathrm{L}^{*}\right)$ of crumb with crust and crustless crumb were $55.96 \pm 1.39$ and $55.79 \pm 0.88$, respectively. Between both $L^{*}$-values there is no significant 
difference. Crumb of crustless bread showed higher a*-values $(4.41 \pm 0.21)$ then crumb of bread with crust (4.27 $\pm 0.21)$. The yellow hue $\left(+b^{*}\right)$ was also higher in crumb of crustless bread $(16.61 \pm 0.46)$ then in crumb of bread with crust $(16.20 \pm 0.40)$. $a^{*}$ - and $b^{*}$-values of both crumbs differed significantly $(p<0.05)$.

Crumb color difference of both bread types was evaluated in terms of $\Delta \mathrm{E}$. The calculated difference between crumb of crustless bread and bread with curst was $\Delta \mathrm{E}=0.47$.

\subsection{Firmness Measurement}

Crumb firmness values of bread with and without crust are shown in Table 2. The firmness of crumb of bread with crust $(22.124 \pm 2.257 \mathrm{~N})$ is higher than crumb of crustless bread $(19.100 \pm 1.637 \mathrm{~N})$. Evaluation of ANOVA shows, that both crumbs differed significantly $(\mathrm{p}<0.05)$.

Table 2. L*a*b*-values and crumb firmness of bread with crust and crustless bread

\begin{tabular}{lcc}
\hline & Crumb of bread with crust & Crumb of crustless bread \\
\hline Color & & \\
$\mathrm{L}^{*}$ & $55.96 \pm 1.39$ & $55.79 \pm 0.88$ \\
$\mathrm{a}^{*}$ & $4.27 \pm 0.21$ & $4.41 \pm 0.21$ \\
$\mathrm{~b}^{*}$ & $16.20 \pm 0.40$ & $16.61 \pm 0.46$ \\
Firmness in N & $22.124 \pm 2.257$ & $19.100 \pm 1.637$ \\
\hline
\end{tabular}

\subsection{Sensory}

The results of triangle test of the two types of bread crumbs are demonstrated in Table 3 . The sensory test shows that 85 triangles out of 148 triangles were detected incorrectly which corresponds to $57.4 \%$ and 63 triangles out of 148 triangles were identified correctly, which corresponds to $42.6 \%$. These results of the triangle test of similarity revealed a similarity between crumb of bread with crust and crumb of bread without crust.

Table 3. Results of triangle test

\begin{tabular}{lll}
\hline & Number of judgments & Expressed as a percentage \\
\hline Correct judgments & 63 & $42.6 \%$ \\
Wrong judgments & 85 & $57.4 \%$ \\
\hline
\end{tabular}

Figure 2 shows, reasons for correct judgments which panelists noted. Thereby it is noted, that $57 \%$ of panelists could differentiate the samples because of differences in texture and $13 \%$ of panelists guessed correct judgment. Just $30 \%$ of panelists identified correct judgments because of differences in flavor.

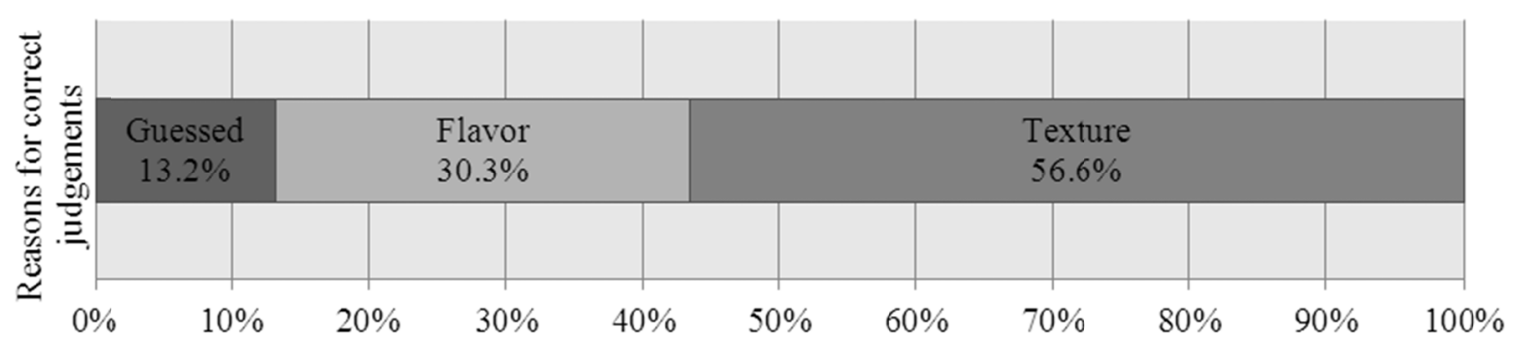

Figure 2. Reasons for correct judgments, which were noted by panelists

\section{Discussion}

\subsection{Color and Firmness}

Color measuring demonstrated that there was no significant difference between both $\mathrm{L}^{*}$-values. However a*and $b^{*}$-values differed significantly. Although color distance $(\Delta E)$ of both crumbs was 0.47 which means that 
the observer cannot see any differences between both colors (Dreher, 2009). Therefore, it is assumed that panelists cannot determine a color difference between crumb of crustless bread and crumb of bread with crust during sensory tests.

Measurement of firmness showed that there was a significant difference of texture between crustless bread and bread with crust, although crumb of crustless bread was softer then crumb of bread with crust. Differences in firmness is the result of a different baking procedure. Crustless bread was baked in stream of water and therefore the texture was softer, like Baik and Chinachoti (2003), Curti, Carini, Bonacini, Tribuzio and Vittadini (2013) and Piazza and Masi (1995) also reported.

Comparing the results of firmness measurement and sensory test, it was recognized that panelists who identified the correct sample, detected correct sample very often $(57 \%)$ due to the difference texture. This relation indicated that a different texture was the major difference between crustless crumb and crumb of bread with crust and not the difference in flavor.

\subsection{Sensory}

The test showed that crumbs of bread baked with and without crust were similar. Thus the results suggest that there was no diffusion of flavor substances from crust to crumb, which was sensory perceptible by panelists.

In contrast to this data, many authors determined slightly milder flavor in crustless bread and stronger flavor in bread baked with crust. Hence they supposed that flavor substances produced in crust during baking diffuse to the crumb (Baker et al., 1939, Baker \& Mize, 1953, Lorenz \& Maga, 1972, Wiseblatt, 1961).

In case of the experiments conducted by Baker and Mize (1939), this difference could be explained by their different way of baking crustless breads. The scientists succeeded in getting crustless breads by heating the dough between electrodes in a field of alternating current whereas in the constant study those breads were baked in steam of water. Providing alternating current heating may possibly produce some flavor active substances in the crumb of those breads. Another difference may be caused by the kind of bread baked. In the present study, $80 \%$ rye bread with $20 \%$ wheat flour enriched with sour dough was made which might be more enriched in flavor than pure wheat flour breads. Nevertheless, this study proves that the widely accepted assumption that the flavor of bread crumb is influenced by the crust is not true in general and is not detectable by sensory tests; at least for rye-breads.

\section{Conclusion}

Low color distance $(\Delta \mathrm{E})$ between both crumbs showed that observers normally cannot see differences between the crumbs. Significant softer texture of crustless crumb indicates that major differences between both bread types are different in texture and not in different flavor.

Sensory comparison of the crumb of crustless breads and breads with crust indicated in this study a similarity of both crumbs. Because many panelists guessed differing sample or recognized differing sample due to different texture, it is assumed that there was no sensory noticeable diffusion of flavor substances from crust to crumb in bread with crust. This data indicates that the generally accepted and taughed assumption that the flavor of crust diffuses into the crumb of bread is, at least for rye-breads, not detectable by sensory tests.

\section{Acknowledgements}

This project (HA project no. 359/12-49) was funded in the framework of Hessen ModellProjekte financed with funds of LOEWE-Landes-Offensive zur Entwicklung Wissenschaftlich-ökonomischer Exzellenz, Förderlinie 3: KMU-Verbundvorhaben.

\section{References}

Baik, M. Y., \& Chinachoti, P. (2003). Water self-diffusion coefficient and staling of white bread as affected by glycerol. Cereal Chem, 80, 740-744. http://dx.doi.org/10.1094/CCHEM.2003.80.6.740

Baker, J. C., \& Mize, M. D. (1939). Some observations regarding the flavor of bread. Cereal Chem, 16, 295-297.

Baker, J. C., Parker, H., \& Fortmann, K. (1953). Flavor of bread. Cereal Chem, 30, 22-30.

Busch-Stockfisch, M. (2003). Dreiecksprüfungen - Triangeltest. In S. Praxishandbuch, M. Busch-Stockfisch, (4th ed., pp. 1-12). Behr's Verlag.

Curti, E., Carini, E., Bonacini, G., Tribuzio, G., \& Vittadini, E. (2013). Effect of the addition of bran fractions on bread properties. J. Cereal Sci, 57, 325-332. http://dx.doi.org/10.1016/j.jcs.2012.12.003

Dreher, A. (2009). Proseminar Farbmanagement - Thema 2 - Grundlagen II. Universität Koblenz-Landau, 
Institut für Computervisualistik.

FoB. (2010). European Bread Market. Retrieved 7. August 2014, from http://www.bakersfederation.org.uk/the-bread-industry/industry-facts/european-bread-market.html

Fillion, L., \& Kilcast, K. (2001). Towards a measurement of oral tactile sensitivity and matication performance: development of texture tests. Leatherhead Food RA Research Report, 781. Surrey (UK): Leatherhead Food.

Heiniö, R-L. (2006). Sensory attributes of bakery products. In Y. H. Hui (Ed.), Bakery products: science and technology (pp. 285-298), Blackwell Publishing. http://dx.doi.org/10.1002/9780470277553.ch16

Heseker, H. (2008). Ernährungssituation in Deutschland. In E. V. (Ed.), Deutsche Gesellschaft für Ernährung Ernährungsbericht 2008. (pp. 26-36). Bonn.

Lindenmeier, M., \& Hofmann, T. (2004). Influence of baking conditions and precursors supplementation on the amounts of the antioxidant pronyl-L-lysine in bakery products. J. Agric. and Food Chem, 52, 350-354. $\mathrm{http}: / / \mathrm{dx}$.doi.org/10.1021/jf0346657

Lorenz, K., \& Maga, J. (1972). Staling of White Bread: and Glc Headspace Profiles. J. Agric. Food Chem, 20(2), 211-213. http://dx.doi.org/10.1021/jf60180a035

Meilgaard, M., Civille, G. V., \& Carr, B. T. (1999). Sensory evaluation techniques (3rd ed.), Boca Raton, CRC Press. http://dx.doi.org/10.1201/9781439832271

Morley, J. E., Glick, Z., \& Rubenstein, L. Z. (1995): Geriatric nutrition: A comprehensive review. (2nd ed.), New York: Raven Press.

Piazza, L., \& Masi, P. (1995). Moisture redistribution throughout the bread loaf during staling and its effect in mechanical properties. Cereal Chem, 72, 320-325.

Quadt, A., Schwarz, M., \& Schönberger, S. (2009). Statistische Auswertungen in der Sensorik. Vol. I, Hamburg, Behr's Verlag: CD-Rom.

Rehrmann, N. (2007). Gut ernährt im Alter. UGB-Forum, 2, 61-65.

Robinson, R. J., Lord, T. H., Johnson, J. A., \& Miller, B. S. (1958). The aerobic microbiological population of pre-ferments and the use of selected bacteria for flavor production. Cereal Chem. 35, 295-305.

Salim-ur-Rehman, Paterson, A. \& Pigott J. R. (2006). Flavour in sourdough breads: a review. Trends Food Sci. Tech., 17, 557-566. http://dx.doi.org/10.1016/j.tifs.2006.03.006

Visser't Hooft, F., \& De Leeuw, F. J. G. (1935). The occurrence of acetylmethylcarbinol in bread and its relation to bread flavor. Cereal Chem, 12, 213-229.

Volkert, D., Kruse, W., Oster, P., \& Schlierf, G. (1991). Malnutrition in geriatric patients: diagnostic and prognostic significance of nutritional parameters. Ann. Nutr. Metab, 36, 97-112. http://dx.doi.org/10.1159/000177704

Wiseblatt, L. (1957). The flavor of bread. Milling Production, 22(1-2), 18-19.

Wiseblatt, L. (1961). Baker's Dig, 35, 5, 60.

\section{Copyrights}

Copyright for this article is retained by the author(s), with first publication rights granted to the journal.

This is an open-access article distributed under the terms and conditions of the Creative Commons Attribution license (http://creativecommons.org/licenses/by/3.0/). 